This article is licensed under the Creative Commons Attribution-NonCommercial 4.0 International License (CC BY-NC) (http://www.karger.com/Services/OpenAccessLicense). Usage and distribution for commercial purposes requires written permission.

\title{
Refractory Septic Shock due to Underlying Immunocompromised Disease: A Case of Fatal Peripheral T-Cell Lymphoma Not Otherwise Specified in a Young Hispanic Woman
}

\author{
Kishore Kumar ${ }^{a, b} \quad$ Muhammad Saad $^{a} \quad$ Chukwunonso Chime $^{a, b}$ \\ Kanthi Badipatla ${ }^{a, b}$ Hassan Tariq ${ }^{a}$ Sureshkumar Nayudu ${ }^{a, b}$ \\ Masooma Niazi ${ }^{c}$ Sridhar Chilimuria, b \\ a Department of Medicine, Bronx Lebanon Hospital Center, Bronx, NY, USA; ${ }^{b}$ Division of \\ Gastroenterology, Bronx Lebanon Hospital Center, Bronx, NY, USA; 'Department of \\ Pathology, Bronx Lebanon Hospital Center, Bronx, NY, USA
}

\section{Keywords}

T-cell lymphoma not otherwise specified $\cdot$ Refractory shock $\cdot$ Non-Hodgkin lymphoma

\begin{abstract}
Peripheral T-cell lymphoma not otherwise specified (PTCL-NOS) is known as an unclassified group of non-Hodgkin lymphomas. PTCL-NOS is a subtype of peripheral T-cell lymphoma that accounts for $3 \%$ of all lymphomas in the United States. PTCL-NOS commonly presents as a disseminated disease, B symptoms (fever, night sweats, and weight loss), generalized lymphadenopathy, bone marrow infiltration, and extranodal involvement. Other rare and possible manifestations include peripheral eosinophilia, pruritus, or hemophagocytic syndrome. This type of lymphoma is aggressive in nature and carries a high mortality rate. There is no estab-
\end{abstract}




\section{Case Reports in Oncology}

Case Rep Oncol 2018;11:404-411

DOI: $10.1159 / 000488312$

2018 The Author(s). Published by S. Karger AG, Basel www.karger.com/cro

Kumar et al.: Refractory Septic Shock due to Underlying Immunocompromised Disease: A Case of Fatal PTCL-NOS

lished standard-of-care treatment protocol for PTCL-NOS, several chemotherapy drug combinations are frequently used as a frontline treatment with an overall 5 -year survival rate of $25 \%$. We present a case of a 35-year old Hispanic woman who initially presented with a chief complaint of bilateral lower extremity swelling due to hypoalbuminemia and new-onset hyperkeratotic skin of the palms and soles.

(C) 2018 The Author(s)

Published by S. Karger AG, Basel

\section{Case Presentation}

A 35-year-old Hispanic woman was admitted to hospital with worsening of bilateral lower extremity swelling for 4 days. Her present medical illness started 1 year ago, and 2 weeks prior to this admission she was seen by her primary care physician who added diuretics to her current treatment (enalapril and hydrochlorothiazide). However, the swelling worsened and prompted her to visit an emergency room. Her medical history included well-controlled hypertension (unknown duration) and non-insulin-dependent diabetes mellitus which was diagnosed 2 years ago and managed with metformin. She reported decreased exercise tolerance limited by tiredness. She also reported intermittent diarrhea triggered by certain foods like white bread for almost 1 year. Review of the system was positive for hair loss, loss of appetite, cold intolerance, and weight loss of 16 pounds in the previous 6 months. She denied fever, shortness of breath, orthopnea, cough, joint pain, dizziness, paresthesia, dysuria, periorbital swelling, and rash. There was no history of tobacco, alcohol, and drug use and she had no known drug or food allergies. Her home medication included enalapril, hydrochlorothiazide, and metformin. Her mother had a history of hypothyroidism. She came to the United States 20 years ago from Guatemala. On physical examination, she appeared mildly anxious with stable vitals and adequate oxygen saturation on ambient air. Her BMI was 33. On examination, she had hyperkeratotic skin involving bilateral palms and soles along with $2+$ bilateral pitting edema up to the level of the thigh. The rest of the physical examination, including cardiovascular, pulmonary, neurological, and abdominal, was completely normal. There were no palpable lymph nodes on physical examination. In the first set of investigations in the emergency room, she was found to have microcytic anemia with hemoglobin of $8.9 \mathrm{~g} / \mathrm{dL}$, mean corpuscular volume of $72.6 \mathrm{fL}$, leukocytosis of $17,000 \mathrm{k} / \mathrm{UL}$ with neutrophils of $84 \%$, hypokalemia $2.8 \mathrm{mEq} / \mathrm{L}$, hypoalbuminemia $2.4 \mathrm{mg} / \mathrm{dL}$, and thyroid-stimulating hormone of 7.34 mIU/L (Table 1, Table 2). Urine analysis and initial chest X-ray were completely normal. During hospitalization, she underwent further investigations to delineate the etiology of peripheral edema, hypoalbuminemia, and diarrhea that included an echocardiogram, which showed ejection fraction of $72 \%$, concentric remodeling, hyperdynamic left ventricle, and trivial pericardial effusion. Ultrasound of the abdomen and pelvis showed mild hepatomegaly, mild fatty infiltration, cholelithiasis, and fibroid uterus, respectively. Ultrasound of the lower extremity showed absence of deep venous thrombosis. For evaluation of anemia and low albumin level, she underwent small bowel enteroscopy and colonoscopy that showed gastric mucosal atrophy and diverticulosis. Gastric biopsy revealed Helicobacter pylori gastritis for which she was started on triple therapy (amoxicillin, clarithromycin, and metronidazole). Stool workup was positive for Strongyloides and she was treated with ivermectin. Further workup for anemia showed no evidence of underlying hemoglobinopathy and an elevated ferritin level was 


\section{Case Reports in Oncology}

Case Rep Oncol 2018;11:404-411

DOI: $10.1159 / 000488312$

(c) 2018 The Author(s). Published by S. Karger AG, Basel www.karger.com/cro

Kumar et al.: Refractory Septic Shock due to Underlying Immunocompromised Disease: A Case of Fatal PTCL-NOS

deemed as acute-phase reactant. Her elevated level of TSH was secondary to subclinical hypothyroidism. On subsequent days, she started spiking fever with tachycardia and hypotension. Hence, a computed tomography (CT) scan of the chest and abdomen was performed that showed bilateral patchy areas of airspace disease, mediastinal lymphadenopathy, splenic lesion of $5.3 \times 3.7 \mathrm{~cm}$; a space-occupying lesion or splenic abscess could not be excluded. Septic workup was sent, and she was started on broad-spectrum antibiotics. CT-guided splenic biopsy performed by an interventional radiologist showed fragments of splenic tissue with marked neutrophilic infiltrate and no evidence of metastatic carcinoma or lymphoma was found. Gram stain showed rare gram-negative bacilli; however, no growth was identified. Bone marrow biopsy was performed suspecting hemophagocytic lymphohistiocytosis or hematologic malignancy. Her hospital course further complicated with respiratory failure necessitating mechanical ventilation, persistent fever, hemodynamic instability, and refractory shock requiring multiple pressor support. Despite all efforts, she remained severely acidotic and succumbed to death on the 13th day of hospitalization. The bone marrow biopsy reported after her demise showed bone marrow infiltration by large pleomorphic atypical lymphocytes, which occupied paratrabecular areas, consistent with malignant T-cell lymphoma. Similarly, postmortem examination of the spleen, pelvic, and paratracheal lymph nodes supported the findings of peripheral T-cell lymphoma not otherwise specified (PTCL-NOS). This case shows that lethal refractory distributive shock is not always due to failure in treating resistant bacteria; rather, it could be due to an underlying undiagnosed immunocompromised state which mounts a weak immune response against an offending agent.

\section{Discussion}

In general, non-Hodgkin lymphomas originate from B lymphocytes in $85-90 \%$ of cases and $10-15 \%$ of cases originate from $\mathrm{T}$ cells and natural killer (NK) cells. T-cell malignancies derived from precursor or immature T cells form leukemia-lymphoblastic T-cell lymphomas, whereas mature T lymphocytes or NK cell malignancies give rise to peripheral T-cell lymphomas (PTCL). According to the World Health Organization (WHO) Classification of Tumors, peripheral $\mathrm{T}$ cells/NK cells comprise 22 different entities categorized according to clinical presentation as primary nodal, primary extranodal, primary cutaneous, and disseminated leukemic forms, as shown in Table 3.

PTCL-NOS represents the most common subtype and accounts for $26 \%$ of all PTCL [1]. It is commonly seen in the Asian and Caribbean region, slightly predominant in men, age $>55$ years, and associated with underlying infection with viruses, including Epstein Barr virus (EBV), human immunodeficiency virus (HIV), and human T-cell leukemia virus-1 [2-4]. The clinical manifestation consists of B symptoms, including fever, generalized lymphadenopathy, fatigue, and unexplained weight loss. Occasionally, pruritis, eosinophilia, and hemophagocytic syndrome can be presenting features of the disease [5]. Disseminated disease including bone marrow involvement is seen in approximately half of the cases at the time of presentation. The skin and gastrointestinal tract represent the most commonly affected extranodal sites. Comprehensive physical examination including lymph nodes, spleen, and liver is warranted at the time of initial presentation. Diagnosis of PTCL-NOS requires a combination of high clinical sus- 


\section{Case Reports in Oncology}

Case Rep Oncol 2018;11:404-411

DOI: $10.1159 / 000488312$

(c) 2018 The Author(s). Published by S. Karger AG, Basel www.karger.com/cro

Kumar et al.: Refractory Septic Shock due to Underlying Immunocompromised Disease: A Case of Fatal PTCL-NOS

picion and histopathological techniques. Excisional lymph node biopsy remains the cornerstone of diagnosis [6]. Needle biopsy guided by imaging is not recommended. After histological diagnosis is made, CT/positron emission tomography imaging and bone marrow biopsy should be performed to determine the extent and progression of the disease. Routine blood tests should include assessment of blood count, beta2-microglobulin, and lactate dehydrogenase (LDH) for prognostic purposes. Testing for HIV, EBV, human T-cell leukemia virus, and hepatitis $\mathrm{B}$ and $\mathrm{C}$ can also be done to determine the causation of the disease. The International Prognostic Index (IPI) is used to assist in determining prognosis before therapy and includes age, serum LDH level, number of extranodal sites, disease stage, and performance status. Patients often present with unfavorable features including B symptoms, elevated LDH levels, high tumor burden, advanced disease (stage III or IV), and poor performance status. Approximately $50-70 \%$ of patients present with a high or high-intermediate IPI score. New prognostic models focusing on bone marrow involvement have been developed but have not been validated yet [7]. Treatment of PTCL-NOS should include prompt diagnosis, aggressive treatment, and vigilant surveillance since it has a fulminant course. Aggressive chemotherapy in the early course of the disease has shown better outcomes. Multiagent chemotherapy with RCHOP (rituximab, cyclophosphamide, hydroxydoxorubicin, Oncovin ${ }^{\circledR}$ [vincristine], prednisone) is the standard regimen, followed by radiotherapy in cases of stage I-II disease with an overall response rate higher than $60 \%$. Given the poor outcome with the R-CHOP regimen, it seems that integration of radiotherapy is a reasonable approach despite a 5 -year overall survival of only 20-30\% [8]. Many other novel agents, including denileukin diftitox-, gemcitabine, and bortezomib-based chemotherapy, have shown optimal response rates between 30 and $60 \%$; however, a detailed explanation is beyond this review [9]. Combination of chemotherapy and autologous/allogenic stem cell transplant has shown survival rates of $40 \%$, but it is associated with significant morbidity [10]. Although the outcomes vary significantly, the prognosis remains poor for high IPI scores with an estimated survival of $30 \%$ after 5 years despite aggressive management [11]. This case is unique in terms of its atypical presentation and mortal clinical course.

\section{Conclusion}

In general, PTCL-NOS is not commonly seen in routine clinical practice and it requires a high index of suspicion for diagnosis. Although more prevalent in middle-aged men, the clinician should also suspect underlying undiagnosed lymphoma in critically ill young patients of any gender with no significant risk factors who do not respond to optimal medical therapy. Diagnosis requires tissue biopsy along with other prognostic markers such as LDH and beta2macroglobulin. Despite aggressive treatment early in the disease course, its prognosis remains guarded. 


\section{Statement of Ethics}

Informed consent was obtained from the patient's next of kin for publication of this case report and any accompanying images. All efforts were made to keep patient information confidential. Patient's name and demographic details are not disclosed anywhere in the manuscript.

\section{Disclosure Statement}

The authors have no conflict of interest.

\section{Author Contributions}

All authors have contributed in writing and reviewing the manuscript.

\section{Funding Sources}

This paper was not funded.

\section{References}

1 Savage KJ, Ferreri AJ, Zinzani PL, Pileri SA. Peripheral T-cell lymphoma-not otherwise specified. Crit Rev Oncol Hematol. 2011 Sep;79(3):321-9.

2 Foss FM, Zinzani PL, Vose JM, Gascoyne RD, Rosen ST, Tobinai K. Peripheral T-cell lymphoma. Blood. 2011 Jun;117(25):6756-67.

3 Swerdlow SH, Campo E, Harris NL et al. WHO classification of tumours of haematopoietic and lymphoid tissues. 4th ed. Lyon: IARC Press; 2008.

4 Burad DK, Therese MM, Nair S. Peripheral T-cell lymphoma: frequency and distribution in a tertiary referral center in South India. Indian J Pathol Microbiol. 2012 Oct-Dec;55(4):429-32.

5 Chan JK. Splenic involvement by peripheral T-cell and NK-cell neoplasms. Semin Diagn Pathol. 2003 May;20(2):105-20.

6 Skarbnik AP, Burki M, Pro B. Peripheral T-cell lymphomas: a review of current approaches and hopes for the future. Front Oncol. 2013 May;3(138):138.

7 Gallamini A, Stelitano C, Calvi R, Bellei M, Mattei D, Vitolo U et al.; Intergruppo Italiano Linfomi. Peripheral T-cell lymphoma unspecified (PTCL-U): a new prognostic model from a retrospective multicentric clinical study. Blood. 2004 Apr;103(7):2474-9.

8 Foss F. Evolving therapy of peripheral T-cell lymphoma. Ther Adv Hematol. 2011 Jun;2(3):161-73.

9 Gisselbrecht C, Lepage E, Molina T, Quesnel B, Fillet G, Lederlin P et al.; Groupe d'Etude des Lymphomes de l'Adulte. Shortened first-line high-dose chemotherapy for patients with poor-prognosis aggressive lymphoma. J Clin Oncol. 2002 May;20(10):2472-9.

10 Reimer P, Ruediger T, Schertlin T et al. Autologous stem cell transplantation as first line therapy in peripheral T cell lymphomas update of a prospective multicenter study. ASH Annual Meeting Abstracts 2004;104.

11 Corradini P, Tarella C, Zallio F, Dodero A, Zanni M, Valagussa P et al. Long-term follow-up of patients with peripheral T-cell lymphomas treated up-front with high-dose chemotherapy followed by autologous stem cell transplantation. Leukemia. 2006 Sep;20(9):1533-8. 
\begin{tabular}{l|l}
\hline DOI: $10.1159 / 000488312$ & (c) 2018 The Author(s). Published by S. Karger AG, Basel
\end{tabular} www.karger.com/cro

Kumar et al.: Refractory Septic Shock due to Underlying Immunocompromised Disease: A Case of Fatal PTCL-NOS

Table 1. Pertinent laboratory data

\begin{tabular}{|c|c|c|c|c|}
\hline & Normal range & Day 1 & Day 4 & Day 6 \\
\hline \multicolumn{5}{|l|}{ Hematology } \\
\hline Hemoglobin, g/dL & $12-16$ & 8.9 & 7.1 & 6.9 \\
\hline Hematocrit, \% & $42-51$ & 28 & 24 & 23 \\
\hline Mean corpuscular volume, fL & $80-96$ & 72.6 & 72.4 & 72.6 \\
\hline White cell count, K/UL & $4.8-10.8$ & 17.6 & 10 & 21 \\
\hline Neutrophil, \% & $40-70$ & 84 & 70 & 58 \\
\hline Lymphocyte, \% & $20-50$ & 7.9 & 21 & 32 \\
\hline Platelets, K/UL & $150-400$ & 183 & 149 & 57 \\
\hline Erythrocyte sedimentation rate, $\mathrm{mm} / \mathrm{h}$ & $0-30$ & 112 & & \\
\hline Haptoglobin, mg/dL & $30-200$ & 514 & & \\
\hline Lactate dehydrogenase, $\mathrm{U} / \mathrm{L}$ & $100-190$ & 1,000 & & \\
\hline Serum iron, $\mu \mathrm{g} / \mathrm{dL}$ & $65-175$ & 37 & & \\
\hline Unsaturated iron binding capacity, $\mu \mathrm{g} / \mathrm{dL}$ & $112 / 346$ & 115 & & \\
\hline Transferrin saturation, \% & & 24 & & \\
\hline Serum ferritin, ng/mL & $13-150$ & 5,000 & & \\
\hline Peripheral smear & & normal & & \\
\hline \multicolumn{5}{|l|}{ Metabolic panel } \\
\hline Sodium, mEq/L & $135-145$ & 134 & 141 & 143 \\
\hline Potassium, $\mathrm{mEq} / \mathrm{L}$ & $3.5-5.0$ & 2.8 & 3.4 & 5.0 \\
\hline Bicarbonate, $\mathrm{mEq} / \mathrm{L}$ & $24-30$ & 30 & 29 & 11 \\
\hline Chloride, mEq/L & $98-108$ & 86 & 102 & 102 \\
\hline Blood urea nitrogen, mg/dL & $6-20$ & 15 & 16 & 27 \\
\hline Creatinine, $\mathrm{mg} / \mathrm{dL}$ & $0.5-1.5$ & 0.8 & 1.0 & 2.9 \\
\hline Calcium, mg/dL & $8.5-10.5$ & 8.4 & & \\
\hline Thyroid-stimulating hormone, mIU/L & $0.40-4.50$ & 7.34 & & \\
\hline Free T3, ng/dL & $60-181$ & 79 & & \\
\hline Free $\mathrm{T} 4, \mu \mathrm{g} / \mathrm{dL}$ & $4.8-10.4$ & 6.5 & & \\
\hline Thyroid-stimulating immunoglobulin, \% & $<140$ & 356 & & \\
\hline Vitamin B12 serum, pg/mL & $243-894$ & 572 & & \\
\hline Vitamin D $250 \mathrm{H}$ serum, $\mathrm{ng} / \mathrm{mL}$ & $30-100$ & $<4$ & & \\
\hline Serum folate, $\mathrm{ng} / \mathrm{mL}$ & $3.0-20.0$ & 5.5 & & \\
\hline \multicolumn{5}{|l|}{ Hepatic panel } \\
\hline Total protein, g/dL & $6.0-8.5$ & 7.4 & 6.0 & 6.0 \\
\hline Albumin, g/dL & $3.2-4.8$ & 2.4 & 2.3 & 2.3 \\
\hline Alanine aminotransferase, $\mathrm{U} / \mathrm{L}$ & $5-40$ & 13 & & \\
\hline Aspartate aminotransferase, $\mathrm{U} / \mathrm{L}$ & $9-36$ & 61 & & \\
\hline Alkaline phosphatase, U/L & $42-98$ & 105 & & \\
\hline Total bilirubin/direct bilirubin, mg/dL & $0.2-1.2 / 0.0-0.3$ & $0.4 / 0.1$ & & \\
\hline Prothrombin time, s & $9.5-12$ & 18 & & \\
\hline Partial thromboplastin time, $\mathrm{s}$ & $26-33$ & 39 & & \\
\hline
\end{tabular}


Table 2. Pertinent laboratory data (continued)

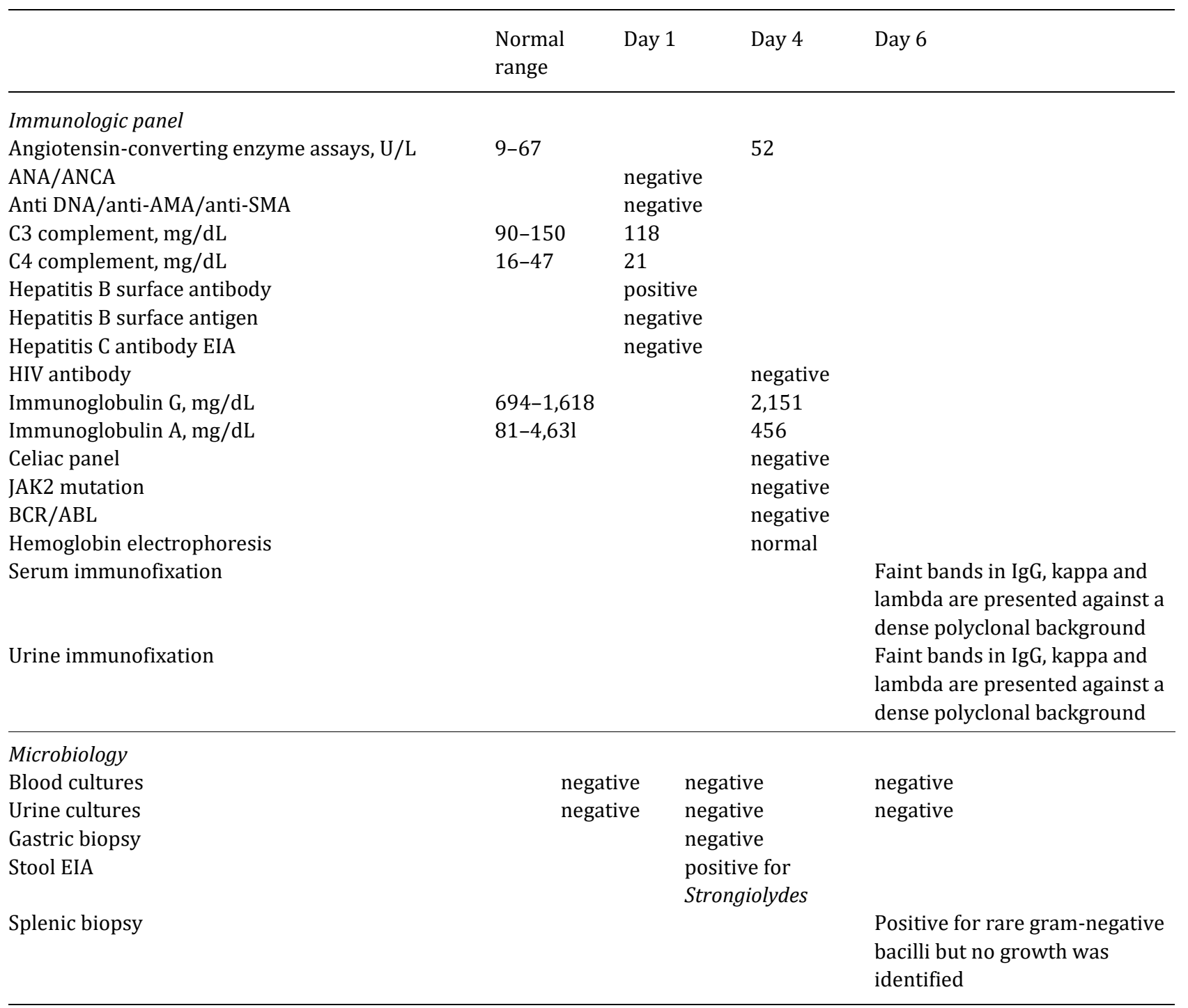


Table 3. World Health Organization classification of peripheral natural killer (NK)/T-cell lymphoma

\section{Primary cutaneous lymphoma}

Mycosis fungoides and Sézary syndrome

Primary cutaneous CD30+ T-cell lymphoproliferative disease

Primary cutaneous anaplastic large cell lymphoma (C-ALCL)

Lymphamatoid papulosis (LYP)

Primary cutaneous peripheral T-cell lymphomas

Gama-delta T-cell lymphoma

$\mathrm{CD}^{+}$aggressive epidermotropic cytotoxic

$\mathrm{CD}^{+}{ }^{+}$small medium

Nodal peripheral T-cell lymphoma (PTCL)

Peripheral T-cell lymphoma not otherwise specified (PTCL-NOS)

Angioimmunoblastic T-cell lymphoma (AITL)

Anaplastic large cell lymphoma (ALCL) anaplastic lymphoma kinase (ALK) positive

Anaplastic large cell lymphoma (ALCL) ALK negative (provisional)

Extranodal peripheral T-cell lymphoma

Extranodal NK T-cell lymphoma, nasal type

Enteropathy associated T-cell lymphoma (EATL)

Hepatosplenic T-cell lymphoma (HSTL)

Subcutaneous panniculitis-like T-cell lymphoma (SPTCL)

Epstein Barr Virus (EBV)-positive T-cell lymphoproliferative childhood disorder

EBV-positive T-cell lymphoproliferative childhood disease

Hydroa vacciniforme-like lymphoma

Widespread or leukemic

T-cell prolymphocytic leukemia (T-PLL)

T-cell large granular lymphocytic leukemia (T-LGL)

Chronic lymphoproliferative disorders of NK cells (provisional)

Aggressive NK cell leukemia

Adult T-cell leukemia/lymphoma 